\title{
Postnatal $N$-acetylcysteine does not provide neuroprotection in extremely low birth weight infants: A follow-up of a randomized controlled trial
}

\author{
Annika Kiuru $^{\mathrm{a}}$, Terhi Ahola ${ }^{\mathrm{b}}$, Liisa Klenberg ${ }^{\mathrm{c}}$, Viena Tommiska ${ }^{\mathrm{b}}$, Aulikki Lano ${ }^{\mathrm{b}}$, Päivi Kleemola ${ }^{\mathrm{b}}$, \\ Anu Haavisto ${ }^{\mathrm{c}, 1}$, Vineta Fellman ${ }^{\mathrm{b}, \mathrm{d}, *, 1}$ \\ ${ }^{a}$ City of Vantaa, Psychological Services for Children, Jönsaksentie 4, 01600 Vantaa, Finland \\ ${ }^{\mathrm{b}}$ Children's Hospital, Helsinki University Hospital, University of Helsinki, Stenbäckinkatu 11, 00290 Helsinki, Finland \\ ${ }^{\mathrm{c}}$ Department of Psychology and Logopedics, University of Helsinki, Haartmaninkatu 3, 00014 Helsinki, Finland \\ ${ }^{\mathrm{d}}$ Department of Clinical Sciences, Pediatrics, Lund University, Klinikgatan 12, 22185 Lund, Sweden, and Folkhälsan Research Center, Biomedicum, Haartmansgatan 8, \\ 00014 Helsinki, Finland
}

\section{Introduction}

Advances in neonatal intensive care have dramatically improved the survival rate for extremely low birth weight (ELBW, $<1000 \mathrm{~g}$ ) infants, but long-term follow-up studies have shown a high risk of neurodevelopmental disabilities, cognitive dysfunction and emotional/behavioural problems [1-4]. Even in children without obvious neurological deficits, subtle abnormalities, such as lower cognitive test scores and poorer academic performance, have been reported compared to normal birth weight controls [5,6]. Areas of cognitive functioning that are particularly affected by ELBW include attention and executive functions [7-9], perceptual-motor abilities and visuospatial processing $[10,11]$. The underlying pathology is termed encephalopathy of prematurity, a combination of white matter damage and neuronal/axonal disease that results in the modification of key developmental pathways in the developing human brain [12]. Suggested mechanism for the common neonatal morbidities, including perinatal brain injury, bronchopulmonary dysplasia (BPD) and retinopathy of prematurity (ROP), is a combination of hypoxia, inflammation, infection and oxidative stress $[13,14]$.

In a multicenter randomized controlled trial, we set out to investigate whether $\mathrm{N}$-acetylcysteine (NAC), an antioxidant, precursor of glutathione and a free radical scavenger [15], decreases these morbidities. The primary outcome measure was BPD defined as oxygen dependence at an age corresponding to 36 gestational weeks [16]. NAC is available as a registered drug to treat acetaminophen poisoning, but it has multiple other uses as well, supported by varying levels of evidence [17]. Studies of the effects of NAC on various neurological disorders or brain functions have mostly been carried out in animal models with only a few studies completed in humans [18]. In rats, NAC has been demonstrated to improve hippocampal neuronal survival after transient forebrain ischemia [19] and reduce the infarct area and volume in a model of experimental stroke [20]. Moreover, it has been shown to provide substantial neuroprotection against perinatal brain injury in newborn rats [21]. In human clinical trials, NAC has been associated with reduced cognitive deficits in patients with probable Alzheimer's disease [22] and mild traumatic brain injury [23]. In addition, there is a growing body of literature of potential benefits of NAC in the treatment of several neuropsychiatric disorders, but many of these studies require replication and are methodologically preliminary [24].

The present study is a one-center long-term follow-up investigation of a Nordic multicenter randomized controlled trial including 391 ELBW infants. The dosage used $(16-32 \mathrm{mg} / \mathrm{kg} / \mathrm{d}$ continuous intravenous NAC infusion over 6 days starting before $36 \mathrm{~h}$ of age) was based on a pharmacokinetic study [25]. The control group received a corresponding placebo infusion with $0.9 \%$ sodium chloride. The sets of vials (10 per infant) to be diluted in glucose and infused were similar for NAC and placebo and the personnel and researchers were blinded to the content. There was no benefit of NAC on the primary combined outcome measure, BPD and death (51 vs $49 \%$ in placebo group) [16]. However, there was a slight, but non-significant difference in cystic periventricular leukomalacia (PVL, 8 vs $11 \%$ ). This motivated us to assess whether NAC would decrease more common, less severe

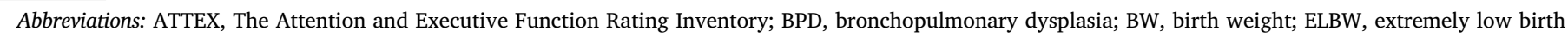

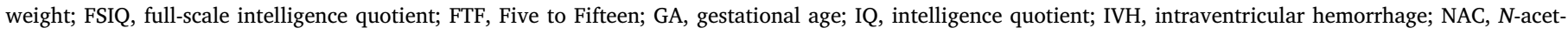

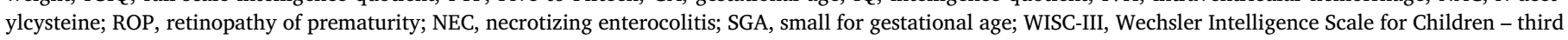
edition

* Corresponding author at: University of Helsinki and Folkhälsan Research Center, Biomedicum-Helsinki C314a, 00014 Helsinki, Finland.

E-mail addresses: annika.kiuru@vantaa.fi (A. Kiuru), terhi.ahola@hus.fi (T. Ahola), liisa.klenberg@helsinki.fi (L. Klenberg), viena.tommiska@hus.fi (V. Tommiska), aulikki.lano@fimnet.fi (A. Lano), paivi.kleemola@helsinki.fi (P. Kleemola), anu.haavisto@helsinki.fi (A. Haavisto), vineta.fellman@helsinki.fi (V. Fellman).

${ }^{1}$ These authors contributed equally to this work. 
neurocognitive sequelae and perform a follow-up study in preadolescence. We hypothesized that the postnatal NAC infusion would decrease the risk of neurocognitive dysfunction.

\section{Materials and methods}

\subsection{Study groups}

The randomized, placebo-controlled multicenter trial of ELBW infants on ventilator or nasal continuous positive airway pressure was conducted in 10 academic intensive care units in Denmark, Finland, Norway, Sweden and Iceland between 1997 and 2001. In total, 194 infants received NAC and 197 placebo for 6 days [16].

The present study is a follow-up of the infants enrolled in the trial at the Helsinki University Children's Hospital in Finland $(n=123)$. Of these, 103 were alive at the time of the follow-up. Parents of 12 children could not be reached; however, for six of these children cognitive status was known from previous cognitive assessments. One family declined participation. Thus, the study group in this follow-up assessment consisted of 96 children (Fig. 1).

\subsection{Follow-up}

\subsubsection{Assessment of neurocognition}

The children were assessed by a psychologist of the Helsinki University Children's Hospital or a trained psychology undergraduate, who were unaware of the patients' treatment assignments in the trial. General cognitive ability was assessed with a short form of the Finnish Wechsler Intelligence Scale for Children - third edition (WISC-III) [26]. Three scales were employed: estimated verbal intelligence quotient (IQ; subtests information, similarities, vocabulary), performance IQ (picture completion, coding, block design), and the combined full-scale IQ (FSIQ). Using the original test standardization norms, the scales have a mean of 100 (SD 15).

The NEPSY-II neuropsychological test battery evaluates cognitive functioning in six domains [27]. A total of 14 age-appropriate subtests from five different domains were administered: the attention and executive functions domain (subtests animal sorting, auditory attention and response set, inhibition); language (comprehension of instructions, phonological processing, word generation); memory and learning (memory for designs, narrative memory, word list interference); sensorimotor (imitating hand positions, visuomotor precision); visuospatial processing (arrows, design copying, geometric puzzles). Domain scores were used in statistical analyses.

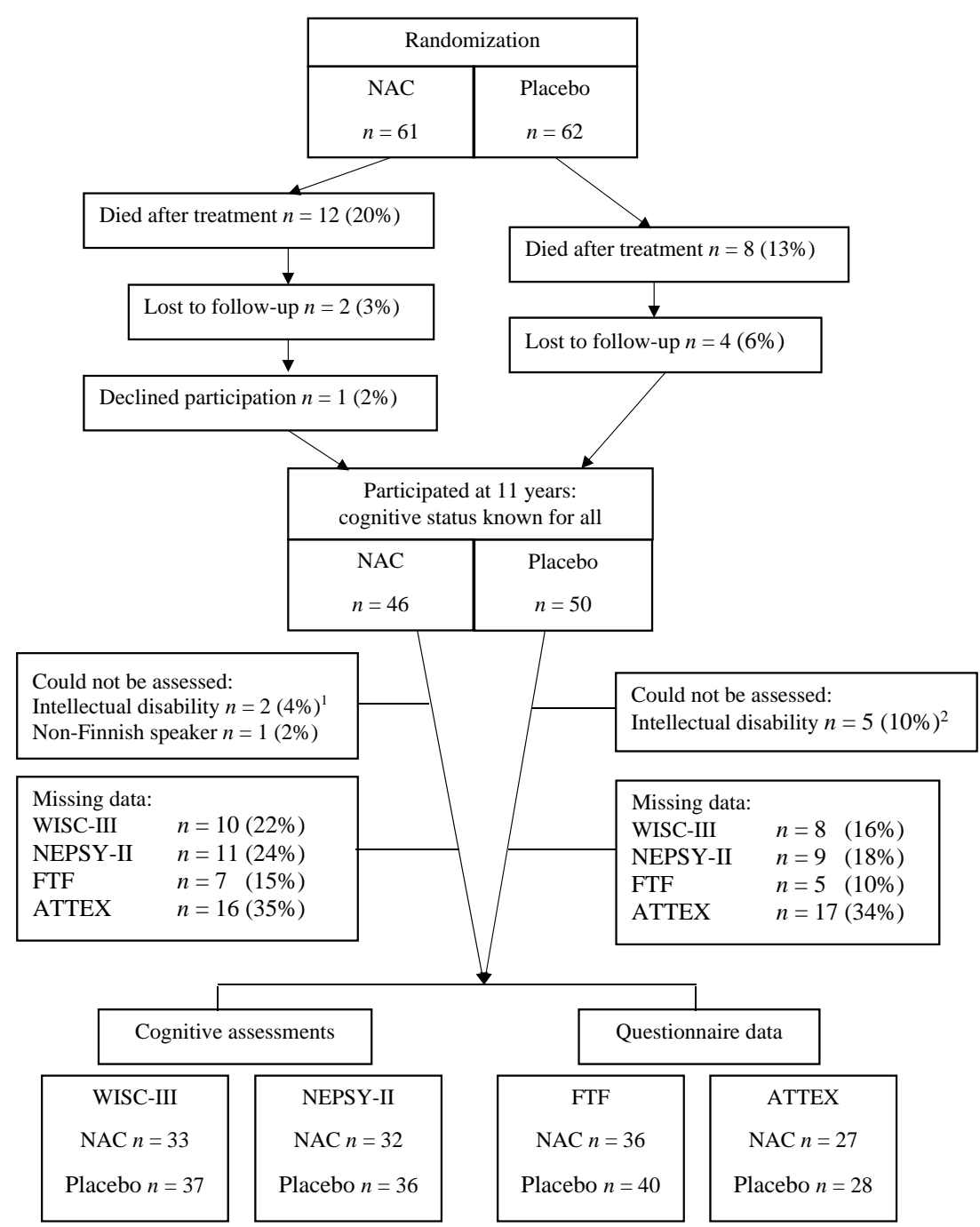

Fig. 1. Flow chart of study participation and non-participating children.

${ }^{1}$ One child additionally had severe cerebral palsy and PVL. ${ }^{2}$ Two children additionally had cerebral palsy and one had autism. 
Table 1

Background characteristics of children included in the follow-up.

\begin{tabular}{|c|c|c|c|}
\hline & $\begin{array}{l}\text { NAC } \\
(n=46)\end{array}$ & $\begin{array}{l}\text { Placebo } \\
(n=50)\end{array}$ & $p$ \\
\hline \multicolumn{4}{|l|}{ At birth } \\
\hline Birthweight (g) & $\begin{array}{l}770.6 \\
(118.2)\end{array}$ & $\begin{array}{l}771.1 \\
(137.7)\end{array}$ & .984 \\
\hline Gestational age (wk) & $26.8(1.8)$ & $26.9(2.0)$ & .724 \\
\hline Maternal age $(y)^{a}$ & $30.4(5.7)$ & $31.2(4.5)$ & .444 \\
\hline Boys & $21(46 \%)$ & $24(48 \%)$ & .840 \\
\hline \multicolumn{4}{|l|}{ At follow-up } \\
\hline Age at study $(y)^{b}$ & $11.4(1.2)$ & $11.1(0.9)$ & .203 \\
\hline Maternal education ${ }^{\mathrm{b}}$ & & & .700 \\
\hline Primary school & $6(15 \%)$ & $4(9 \%)$ & \\
\hline Vocational school & $11(28 \%)$ & $9(21 \%)$ & \\
\hline $\begin{array}{l}\text { Upper secondary school or vocational } \\
\text { college }\end{array}$ & $11(28 \%)$ & $14(33 \%)$ & \\
\hline $\begin{array}{l}\text { University or university of applied } \\
\text { sciences }\end{array}$ & $12(30 \%)$ & $16(37 \%)$ & \\
\hline \multicolumn{4}{|l|}{ Risk factors } \\
\hline Small for gestational age & $23(50 \%)$ & $24(48 \%)$ & 1.00 \\
\hline Periventricular leukomalacia & $3(7 \%)$ & $4(8 \%)$ & 1.00 \\
\hline Intraventricular hemorrhage, grade $\geq 2$ & $8(17 \%)$ & $8(16 \%)$ & 1.00 \\
\hline Necrotizing enterocolitis, grade $\geq 3$ & $7(15 \%)$ & $7(14 \%)$ & 1.00 \\
\hline Retinopathy of prematurity, grade $\geq 2$ & $19(41 \%)$ & $23(46 \%)$ & .684 \\
\hline $\begin{array}{l}\text { Oxygen dependency at the age } \\
\text { corresponding to } 36 \text { gestational weeks }\end{array}$ & $20(44 \%)$ & $17(34 \%)$ & .403 \\
\hline
\end{tabular}

Values are mean (SD) or $n(\%)$

a Data missing for one child in the NAC group.

b Data not known for 6 children in the NAC and 7 in the control group whose cognitive status was based on hospital records.

\subsubsection{Questionnaires}

A standardized parental questionnaire (Five to Fifteen, FTF $[28,29]$ ) was sent to the families to be completed before the formal assessment. The questions have been designed to evaluate developmental problems in children aged five to fifteen years. In this study, 25 items of the executive functions domain were used, which were compiled into four subscales according to manual instructions. Lower scores indicate better outcome.

Another questionnaire was sent to the teachers (The Attention and Executive Function Rating Inventory, ATTEX [30]). ATTEX is a teacher rating scale with 55 items in 10 domains describing difficulties of inhibition, attention, and executive functions in the school setting. Lower scores indicate better outcome.

\subsubsection{Background data collection and ethics}

The perinatal and neonatal data (including grading of the medical risk factors) was obtained from the initial trial database. In the original study, intraventricular hemorrhage (IVH) was classified according to the criteria of Papile et al. [31], PVL according to the criteria of Trounce et al. [32], necrotizing enterocolitis (NEC) grade III or higher (NEC needing surgical treatment) according to Bell et al. [33], and ROP classified as the stage of disease in the more severely affected eye, based on the International Classification of Retinopathy of Prematurity [34]. Neurological assessment was not carried out in this follow-up study. The current demographic data was collected from the parents. For the children who did not participate in the formal neurocognitive assessments, follow-up data was collected from hospital records with parental permission. Approval to conduct this study was granted by the ethical committee of the Helsinki University Children's Hospital and the National Medical Products Agency. Written informed consent was obtained from the children and their parents.

\subsection{Statistical analyses}

Background variables were compared using the independent samples $t$-test for continuous variables and the exact $\chi^{2}$-test for categorical data. Group differences in outcome variables were compared using general linear model. The presented analyses were controlled for sex and maternal education (divided into 4 classes). An additional analysis controlled for gestational age (GA), small for gestational age (SGA), IVH grades 2-4, ROP grades 2-4, NEC grades 3-4 and oxygen dependency at the age corresponding to 36 gestational weeks (indicator of BPD) was performed to analyse the effect of these risk factors.

In the neurocognitive data, seven children had 5.0 to $10.0 \%$ missing subtest results; these were estimated with the expectation maximisation algorithm [35]. The same procedure was used for FTF and ATTEX (1 child with $4.0 \%$ and 6 children with 1.8 to $9.1 \%$ missing values, respectively). Statistical analyses were performed using IBM SPSS Statistics 24.0 software (SPSS Inc., Chicago, Illinois, USA). All significance tests were two-tailed, and $p<.05$ was considered significant. Partial eta-squared $\left(\eta_{\mathrm{p}}^{2}\right)$ served as an indicator of effect size.

\section{Results}

\subsection{Study population}

The number of deaths in the NAC and placebo groups was $12(20 \%)$ and $8(13 \%)$ children (Fig. 1), respectively (exact $\chi^{2}(1)=1.035$, $p=.309$ ). Of the 103 survivors, some cognitive outcome data was available for 96 (93\%) children (46 (94\%) in the NAC and 50 (93\%) in the placebo group, exact $\left.\chi^{2}(1)=0.067, p=1.00\right)$. The participants and non-participants were compared with respect to medical risk factors, but no differences emerged.

There were no statistically significant differences in the background characteristics or neonatal complications between the participating children in the treatment groups (Table 1). Of the 96 children, seven were severely impaired and one did not speak Finnish and could not be assessed. Families of 16 children declined to participate in the formal neurocognitive assessment but completed questionnaire data or gave their permission to collect data from hospital records. In addition, two children participating in the formal assessment were excluded due to incomplete testing. Thus, a complete assessment of neurocognition was obtained in 70 children. Parental and teacher questionnaires were available for 76 and 55 children, respectively (Fig. 1).

\subsection{Cognitive status}

We allocated the 96 children with some outcome data into three outcome groups based on the formal assessment (complete $n=70$, incomplete $n=2$ ) or hospital data (previous neurocognitive assessment, $n=20$ ). If both were missing, the allocation was based on the FTF questionnaire (whole version, $n=4$ ). All four children allocated based on the FTF had very few parent-reported developmental problems, thus their outcome was defined as normal.

1) Normal outcome: FSIQ $\geq 85$, no specific impairments (both verbal and performance IQ $\geq 70$ ).

2) Mild to moderate dysfunction: FSIQ 70-84, or a specific impairment (verbal or performance IQ $<70$ despite average FSIQ).

3) Severe dysfunction: FSIQ $<70$ or a diagnosed severe impairment (e.g. intellectual disability).

There were no statistically significant differences in cognitive status between the treatment groups (exact $\chi^{2}(2)=0.364, p=.851$; Table 2 ).

\subsection{Neurocognitive test performance}

Of the 70 children who underwent neurocognitive assessment, there were no significant differences in general cognitive ability (WISC-III) between the groups, $F(3,63)=0.44, p=.726$; Wilk's $\Lambda=0.980$, $\eta_{\mathrm{p}}{ }^{2}=0.020$. Similarly, in specific neurocognitive skills (NEPSY-II), no significant group differences were observed, $F(5,58)=0.60, p=.699$; 
Table 2

Numbers (\%) of children with normal or impaired cognitive status in the study groups.

\begin{tabular}{lcc}
\hline Cognitive status & $\begin{array}{l}\text { NAC } \\
(n=46)\end{array}$ & $\begin{array}{l}\text { Placebo } \\
(n=50)\end{array}$ \\
\hline $\begin{array}{l}\text { Normal: FSIQ } \geq 85 \text {, no specific impairments } \\
\begin{array}{c}\text { Mild to moderate dysfunction: FSIQ }<85 \text { or a specific } \\
\text { impairment (verbal or performance IQ }<70)\end{array}\end{array}$ & $\begin{array}{c}33(72 \%) \\
8(17 \%)\end{array}$ & $\begin{array}{c}36(72 \%) \\
7(14 \%)\end{array}$ \\
\begin{tabular}{l} 
Severe dysfunction: FSIQ $<70$ \\
\hline
\end{tabular} & $5(11 \%)$ & $7(14 \%)$ \\
\hline
\end{tabular}

Table 3

Mean values (SD) between study groups for all outcome variables from Bonferroni corrected post hoc-tests.

\begin{tabular}{|c|c|c|c|}
\hline Test & NAC & Placebo & $p$ \\
\hline \multicolumn{4}{|l|}{ Index/subdomain } \\
\hline General cognitive ability & $(n=33)$ & $(n=37)$ & \\
\hline Verbal IQ & $100.1(17.6)$ & $100.2(18.8)$ & .985 \\
\hline Performance IQ & $80.3(20.1)$ & $84.0(21.4)$ & .426 \\
\hline Full-scale IQ & $90.0(15.8)$ & $92.0(16.8)$ & .601 \\
\hline Specific neurocognitive skills & $(n=32)$ & $(n=36)$ & \\
\hline Executive functions & $7.5(2.1)$ & $8.0(2.3)$ & .277 \\
\hline Language & $8.4(1.9)$ & $8.6(2.1)$ & .696 \\
\hline Memory & $8.2(2.4)$ & $7.9(2.6)$ & .614 \\
\hline Sensorimotor functions & $7.6(2.8)$ & $7.6(3.0)$ & .939 \\
\hline Visuospatial functions & $7.1(2.4)$ & $7.6(2.5)$ & .368 \\
\hline Parent report & $(n=36)$ & $(n=40)$ & \\
\hline Attention/concentration & $6.8(5.0)$ & $6.3(5.3)$ & .690 \\
\hline Overactivity/impulsivity & $3.6(4.1)$ & $3.2(4.4)$ & .678 \\
\hline Passivity/inactivity & $2.3(1.9)$ & $1.7(2.0)$ & .134 \\
\hline Planning/organizing & $1.8(1.7)$ & $1.6(1.8)$ & .579 \\
\hline Teacher report & $(n=27)$ & $(n=28)$ & \\
\hline Distractibility & $2.1(1.8)$ & $1.4(1.9)$ & .164 \\
\hline Impulsivity & $4.3(4.2)$ & $2.4(4.5)$ & .113 \\
\hline Motor hyperactivity & $1.8(1.9)$ & $0.8(2.1)$ & .063 \\
\hline Directing attention & $3.0(2.8)$ & $2.7(2.9)$ & .717 \\
\hline Sustaining attention & $2.6(3.2)$ & $2.3(3.4)$ & .694 \\
\hline Shifting attention & $1.9(2.1)$ & $1.8(2.2)$ & .949 \\
\hline Initiative & $2.8(2.7)$ & $2.3(2.9)$ & .484 \\
\hline Planning & $2.1(2.0)$ & $1.3(2.1)$ & .151 \\
\hline Execution of action & $3.7(3.7)$ & $3.1(3.9)$ & .555 \\
\hline Evaluation & $1.5(1.4)$ & $1.0(1.5)$ & .211 \\
\hline
\end{tabular}

Wilk's $\Lambda=0.951, \eta_{\mathrm{p}}{ }^{2}=0.049$. For Bonferroni corrected post hoc-analyses, see Table 3. These results remained after controlling for GA, SGA, IVH, ROP, NEC and oxygen dependency. None of the risk factors had a significant impact on the test results.

When comparing the background characteristics of the children with a complete assessment to the children with data on cognitive status but who did not participate in the formal assessment, the proportion of children with severe dysfunction in cognitive status and the prevalence of PVL was significantly higher among the 13 children in the placebo group who did not participate in the formal assessment than those 37 who participated (exact $\chi^{2}(2)=8.81, p=.020$ and exact $\left.\chi^{2}(1)=5.43, p=.049\right)$. No differences emerged in the NAC group.

\subsection{Parental and teacher evaluations}

In parental questionnaires (FTF), there were no significant group differences in executive functions, $F(4,67)=0.79, p=.538$; Wilk's $\Lambda=0.955, \eta_{\mathrm{p}}{ }^{2}=0.045$, when controlling for sex and maternal education. Similarly, in teacher reports (ATTEX), no significant group differences were observed, $F(10,40)=0.98, p=.476$; Wilk's $\Lambda=0.803$, $\eta_{\mathrm{p}}{ }^{2}=0.197$. For Bonferroni corrected post hoc-analyses, see Table 3 . However, when controlling for GA, SGA, IVH, ROP, NEC and oxygen dependency, a main effect of group emerged in ATTEX, $F(10$, $32)=2.17, p=.047$; Wilk's $\Lambda=0.596, \eta_{p}{ }^{2}=0.404$, with less symptoms of attention and executive dysfunction in the placebo group. In
Bonferroni corrected post hoc tests, the difference was significant in only one of 10 domains: distractibility $(p=.025)$. Of the risk factors, ROP had a significant impact on overall test results of the FTF, $F(4$, 59) $=2.86, p=.031$; Wilk's $\Lambda=0.838, \eta_{\mathrm{p}}{ }^{2}=0.162$.

\section{Discussion}

With the aim to decrease oxidative stress in very preterm infants, we performed a randomized controlled trial of continuous intravenous infusion of NAC or placebo. In this study of a secondary outcome measure, neurocognition at 11 years of age, there were no statistically significant differences between the treatment arms, except for slightly less teacher-reported symptoms of distractibility in the placebo group. The clinical importance of this finding is, however, minimal. This study is the first trial to assess the long-term benefit of postnatal NAC administration in ELBW infants.

In experimental animal studies and human clinical trials, potential neuroprotective effects of NAC have been observed [19-23]. There are several possible explanations for the contradictory results of this study. First, the number of studies of the effects of intravenous NAC on children is small and, thus, the evidence is limited. Therefore, it is not known how the immature brain reacts to NAC. In the initial trial, the change in plasma total cysteine concentration during the NAC infusion did not differ from that in the placebo infants, which might indicate that intravenous NAC is poorly deacetylated in preterm infants and so is unable to act as a glutathione precursor and as an antioxidant [16]. In addition, the effects of factors in design and implementation of the initial trial (dosage, timing and duration of intervention) remain unclear.

Second, methodological issues in the present study may influence the results. A possible confounder is linked to the representativeness of our study groups. In studies of preterm infants, it is common that more families with low socioeconomic background but also patients with lower cognitive abilities drop out of studies [36]. In this study, the cognitive status was not known for the 7 children lost to follow-up or whose families declined participation. However, among the children with data on cognitive status but who did not participate in the formal neurocognitive assessment, there was an over-representation of children with adverse cognitive outcome and PVL in the placebo group among those children who did not participate in formal assessments. Nevertheless, the cognitive status of the 96 children did not differ between the NAC and the placebo groups. Hence, we can expect that this selection effect did not obscure the actual differences in neurocognitive performance between the study groups.

The strengths of the present study include its randomized, doubleblind, placebo-controlled design. The participation rates among survivors remained high ( $94 \%$ for NAC and $93 \%$ for placebo groups) despite the extended follow-up time. The neurocognitive assessments were comprehensive and utilised tests that are frequently used in clinical work. Parental and teacher evaluations of executive functions in home and school settings provide additional information on possible cognitive deficits. Further, the data records concerning neonatal variables were systematic and the analyses were adjusted for several confounding factors.

A limitation of this study is that the sample size was relatively small, which might not yield enough statistical power; hence, only large effect sizes would be expected to yield statistically significant differences between the groups. Since this is the first study to assess the influence of NAC treatment on cognitive outcome in ELBW children, this will set a benchmark that possible future studies can use when doing power analysis and determining sample size. Only children from one participating center were included in this study, but they represent one third of all included infants and the standardized assessments could be designed to strictly adhere to the one-center protocol, without problems arising of regional and language differences. It is unlikely that there would be a statistically significant difference in neurocognitive test 
performance if all survivors in the different countries were assessed. Moreover, a small difference in a large sample would not be clinically relevant for recommending a prophylactic NAC infusion over the first week of life to all ELBW infants.

\section{Conclusion}

This is the first randomized controlled trial of postnatal administration of NAC in ELBW infants. NAC treatment did not improve neurocognitive functioning in preadolescence. The use of NAC in the neonatal care of ELBW children is not justifiable. However, this study sets a benchmark for future studies in larger populations.

\section{Declarations of interest}

None.

\section{Acknowledgements}

The authors would like to thank all the participants and their parents for their willingness to be included in the study.

\section{Contributorship statement}

VF and TA designed the data collection instruments, VF and PK coordinated and supervised data collection, VT, TA and PK participated in the acquisition of data, AK, $\mathrm{AH}, \mathrm{VF}$ and $\mathrm{LK}$ conceptualized and designed the study, AH carried out the analysis of the data, AK, AH, LK, $\mathrm{AL}$ and VF interpreted the data, AK drafted the initial manuscript and all authors reviewed and revised the manuscript. All authors approved the final manuscript as submitted and agree to be accountable for all aspects of the work.

\section{Conflict of interest statement}

None declared.

\section{Funding}

This study was supported by grants from the Signe and Ane Gyllenberg Foundation, Medicinska Understödsföreningen Liv och Hälsa r.f., and Finska läkaresällskapet (VF). The study sponsors were not involved in the study design; data collection, analysis, and interpretation; the writing of the manuscript; or the decision to submit the manuscript for publication.

\section{References}

[1] H.G. Taylor, N. Klein, D. Drotar, M. Schluchter, M. Hack, Consequences and risks of $<1000-\mathrm{g}$ birth weight for neuropsychological skills, achievement, and adaptive functioning, J. Dev. Behav. Pediatr. 27 (2006) 459-469.

[2] S. Johnson, C. Hollis, N. Marlow, V. Simms, D. Wolke, Screening for childhood mental health disorders using the strengths and difficulties questionnaire: the validity of multi-informant reports, Dev. Med. Child Neurol. 56 (2014) 453-459.

[3] L.J. Orchinik, H.G. Taylor, K.A. Espy, N. Minich, N. Klein, T. Sheffield, et al., Cognitive outcomes for extremely preterm/extremely low birth weight children in kindergarten, J. Int. Neuropsychol. Soc. 17 (2011) 1067-1079.

[4] C.E. Mercier, M.S. Dunn, K.R. Ferrelli, D.B. Howard, R.F. Soll, Neurodevelopmental outcome of extremely low birth weight infants from the Vermont Oxford network: 1998-2003, Neonatology 97 (2010) 329-338.

[5] P. Anderson, L.W. Doyle, Neurobehavioral outcomes of school-age children born extremely low birth weight or very preterm in the 1990s, JAMA 289 (2003) $3264-3272$.

[6] J.S. Litt, H.G. Taylor, S. Margevicius, M. Schluchter, L. Andreias, M. Hack, Academic achievement of adolescents born with extremely low birth weight, Acta Paediatr. 101 (2012) 1240-1245.

[7] A. Farooqi, B. Hägglöf, F. Serenius, Behaviours related to executive functions and learning skills at 11 years of age after extremely preterm birth: a Swedish national prospective follow-up study, Acta Paediatr. 102 (2013) 625-634.

[8] P.J. Anderson, C.R. Luca, E. Hutchinson, M.M. Spencer-Smith, G. Roberts, L.W. Doyle, et al., Attention problems in a representative sample of extremely preterm/extremely low birth weight children, Dev. Neuropsychol. 36 (2011) 57-73.

[9] H. Mulder, N.J. Pitchford, M.S. Hagger, N. Marlow, Development of executive function and attention in preterm children: a systematic review, Dev. Neuropsychol. 34 (2009) 393-421.

[10] J.F. de Kieviet, J.P. Piek, C.S. Aarnoudse-Moens, J. Oosterlaan, Motor development in very preterm and very low-birth-weight children from birth to adolescence: a meta-analysis, JAMA 302 (2009) 2235-2242.

[11] N. Marlow, E.M. Hennessy, M.A. Bracewell, D. Wolke, Motor and executive function at 6 years of age after extremely preterm birth, Pediatrics 120 (2007) 793-804.

[12] J.J. Volpe, Brain injury in premature infants: a complex amalgam of destructive and developmental disturbances, Lancet Neurol. 8 (2009) 110-124.

[13] Y. Ozsurekci, K. Aykac, Oxidative stress related diseases in newborns, Oxidative Med. Cell. Longev. 2016 (2016) 1-9.

[14] E.S. Twilhaar, J.F. de Kieviet, C.S. Aarnoudse-Moens, R.M. van Elburg, J. Oosterlaan, Academic performance of children born preterm: a meta-analysis and meta-regression, Arch. Dis. Child. Fetal Neonatal Ed. 103 (2018) F322-F330.

[15] G.S. Kelly, Clinical applications of N-acetylcysteine, Altern. Med. Rev. 3 (1998) 114-127.

[16] T. Ahola, R. Lapatto, K.O. Raivio, B. Selander, L. Stigson, B. Jonsson, et al., Nacetylcysteine does not prevent bronchopulmonary dysplasia in immature infants: a randomized controlled trial, J. Pediatr. 143 (2003) 713-719.

[17] J.S. Deepmala, J. Slattery, N. Kumar, L. Delhey, M. Berk, O. Dean, et al., Clinical trials of $\mathrm{N}$-acetylcysteine in psychiatry and neurology: a systematic review, Neurosci. Biobehav. Rev. 55 (2015) 294-321.

[18] R. Bavarsad Shahripour, M.R. Harrigan, A.V. Alexandrov, $N$-acetylcysteine (NAC) in neurological disorders: mechanisms of action and therapeutic opportunities, Brain and Behavior 4 (2014) 108-122.

[19] N.W. Knuckey, D. Palm, M. Primiano, M.H. Epstein, C.E. Johanson, N-acetylcysteine enhances hippocampal neuronal survival after transient forebrain ischemia in rats, Stroke 26 (1995) 305-311.

[20] M. Khan, B. Sekhon, M. Jatana, S. Giri, A.G. Gilg, C. Sekhon, et al., Administration of $\mathrm{N}$-acetylcysteine after focal cerebral ischemia protects brain and reduces inflammation in a rat model of experimental stroke, J. Neurosci. Res. 76 (2004) 519-527.

[21] X. Wang, P. Svedin, C. Nie, R. Lapatto, C. Zhu, M. Gustavsson, et al., $\mathrm{N}$-acetylcysteine reduces lipopolysaccharide-sensitized hypoxic-ischemic brain injury, Ann. Neurol. 61 (2007) 263-271.

[22] J.C. Adair, J.E. Knoefel, N. Morgan, Controlled trial of N-acetylcysteine for patients with probable Alzheimer's disease, Neurology 57 (2001) 1515-1517.

[23] M.E. Hoffer, C. Balaban, M.D. Slade, J.W. Tsao, B. Hoffer, Amelioration of acute sequelae of blast induced mild traumatic brain injury by $N$-acetylcysteine: a doubleblind, placebo controlled study, PLoS One 8 (2013) e54163.

[24] M. Berk, G.S. Malhi, L.J. Gray, O.M. Dean, The promise of N-acetylcysteine in neuropsychiatry, Trends Pharm Sci 34 (2013) 167-177.

[25] T. Ahola, V. Fellman, R. Laaksonen, J. Laitila, R. Lapatto, P.J. Neuvonen, et al., Pharmacokinetics of intravenous $\mathrm{N}$-acetylcysteine in preterm new-born infants, Eur J. Clin. Pharmacol. 55 (1999) 645-650.

[26] D. Wechsler, Wechsler Intelligence Scale for Children-Third edition. [Manual]. Helsinki, Finland: Psykologien Kustannus Oy; 1999.

[27] M. Korkman, U. Kirk, S.L. Kemp, NEPSY II-Lasten neuropsykologinen tutkimus, [NEPSY-II manual] Psykologien Kustannus Oy, Helsinki, Finland, 2008.

[28] B. Kadesjö, L.-O. Janols, M. Korkman, K. Mickelsson, G. Strand, A. Trillingsgaard, et al., The FTF (Five to Fifteen): the development of a parent questionnaire for the assessment of ADHD and comorbid conditions, Eur Child Adolesc Psychiatry 13 (Suppl. 3) (2004) 3-13.

[29] M. Korkman, B. Kadesjö, A. Trillingsgaard, L-O. Janols, K. Mickelsson, G. Strand, et al., Viivi (5-15) - käsikirja. [Five to Fifteen manual]. Helsinki, Finland: ADHDliitto ry; 2005.

[30] L. Klenberg, S. Jämsä, T. Häyrinen, P. Lahti-Nuuttila, M. Korkman, The attention and executive function rating inventory (ATTEX): psychometric properties and clinical utility in diagnosing ADHD subtypes, Scand. J. Psychol. 51 (2010) 439-448.

[31] L.A. Papile, J. Burstein, R. Burstein, R, H. Koffler, incidence and evolution of subependymal and intraventricular hemorrhage: a study of infants with birth weights less than 1,500 g, J. Pediatr. 92 (1978) 529-534.

[32] J.Q. Trounce, N. Rutter, M.I. Levene, Periventricular leucomalacia and intraventricular haemorrhage in the preterm neonate, Arch. Dis. Child. 61 (1986) 1196-1202.

[33] M.J. Bell, J.L. Ternberg, R.D. Feigin, J.P. Keating, R. Marshall, L. Barton, et al., Neonatal necrotizing enterocolitis: therapeutic decisions based upon clinical staging, Ann. Surg. 187 (1978) 1-7.

[34] The Committee for Classification of Retinopathy of Prematurity, An international classification of retinopathy of prematurity, Arch. Ophthalmol. 102 (1984) 1130-1135.

[35] A.P. Dempster, N.M. Laird, D.B. Rubin, Maximum likelihood from incomplete data via the EM algorithm, J Royal Stat Soc (Series B) 39 (1977) 1-38.

[36] L.D. Breeman, J. Jaekel, N. Baumann, P. Bartmann, D. Wolke, Preterm cognitive function into adulthood, Pediatrics 136 (2015) 415-423. 